\title{
PERÍODO DE ENRAIZAMENTO DE MINIESTACAS DE EUCALIPTO PROVENIENTES DE DIFERENTES LÂMINAS DE IRRIGAÇÃO EM MINIJARDIM
}

\author{
MINICUTTINGS ROOTING TIME OF EUCALYPTUS FROM MINIGARDENS MANAGED WITH \\ DIFFERENT WATER IRRIGATION LEVELS
}

\author{
Sula Janaína de Oliveira Fernandes ${ }^{1}$ Reynaldo Campos Santana ${ }^{2}$ Enilson de Barros Silva ${ }^{3}$ Cláudio \\ Márcio Pereira de Souza ${ }^{4}$ Crodoaldo Telmo da Silva ${ }^{5}$
}

\begin{abstract}
RESUMO
Conhecer o tempo ótimo de enraizamento de miniestacas reduz o potencial de doenças e otimiza a utilização da casa de vegetação e de sombra. O objetivo do presente trabalho foi determinar o período de enraizamento das miniestacas de clone híbrido de Eucalyptus urophylla S.T. Blake e Eucalyptus grandis W. Hill ex Maiden na casa de vegetação e de sombra provenientes de minicepas submetidas a diferentes lâminas de irrigação aplicadas em minijardim e com e sem redução foliar da miniestaca. $\mathrm{O}$ experimento foi conduzido no viveiro da Empresa Sada Bio-Energia e Agricultura Ltda., Sete Lagoas-MG. O experimento foi instalado em delineamento em blocos casualizados no arranjo fatorial, composto por sete lâminas de irrigação e com e sem redução foliar. Os tratamentos foram definidos de acordo com a leitura diária do tanque Classe A ( $\mathrm{T} 1=50 \%$ da ET0 - frequência única; T2 $=75 \%$ da ET0 - duas vezes ao dia; T3 $=100 \%$ da ET0 - duas vezes ao dia; T4 $=125 \%$ da ET0 - três vezes ao dia; T5 $=150 \%$ da ET0 - três vezes ao dia; T6 $=100 \%$ da ET0 - frequência única e T7- operacional da empresa - lâmina 10,66 mm dia ${ }^{-1}$, fertirrigação oito vezes ao dia, durante cinco minutos com uma vazão de $0,8 \mathrm{~L} \mathrm{~h}^{-1}$ ). Foram avaliadas nas idades de 10, 20, 30, 40 e 50 dias, as variáveis massa seca da parte aérea, radicular e total. A lâmina de $2,19 \mathrm{~mm} \mathrm{dia}^{-1}$ (T2) sem redução foliar apresentou menor tempo de enraizamento. $\mathrm{O}$ tratamento sem redução foliar proporcionou minimização do tempo de enraizamento para todas as lâminas de irrigação.
\end{abstract}

Palavras-chave: propagação vegetativa; massa seca; tanque Classe A.

\section{ABSTRACT}

Knowing the rooting optimum time reduces the potential for diseases and optimizes the use of greenhouse and shade. The aim of this study was to determine rooting period of the hybrid clone of cuttings of Eucalyptus urophylla S.T. Blake and Eucalyptus grandis W. Hill ex Maiden in the greenhouse and shade from different water irrigation level managements applied in minigardens and with two levels of foliar reduction in the minicuttings. The experiment was conducted in the nursery of the Sada Bio Energy and Agriculture Company, Sete Lagoas, Minas Gerais state, Brazil. The experiment was conducted in a randomized block design in factorial arrangement, consisting of seven irrigation management and reduced levels of two leaves (with and without reduction). The treatments were defined according to the daily reading of the Class A tank $(\mathrm{T} 1=50 \%$ ET0 - single frequency, T2 $=75 \%$ ET0 - twice a day, T3 $=100 \%$ ET0 - twice a day,

1 Engenheira Florestal, MSc., Doutoranda do Programa em Ciência Florestal, Universidade Federal dos Vales do Jequitinhonha e Mucuri, MGT 367, Km 583, CEP 39100-000, Diamantina (MG), Brasil. sulafernandes@hotmail. com

2 Engenheiro Florestal, PhD., Professor Adjunto da Universidade Federal dos Vales do Jequitinhonha e Mucuri, MGT 367, Km 583, CEP 39100-000, Diamantina (MG), Brasil. silviculturaufvjm@yahoo.com.br

3 Engenheiro Agrônomo, PhD., Professor Adjunto da Universidade Federal dos Vales do Jequitinhonha e Mucuri, MGT 367, Km 583, CEP 39100-000, Diamantina (MG), Brasil. ebsilva@ufvjm.edu.br

4 Engenheiro Agrícola, Dr., Professor Adjunto da Universidade Federal dos Vales do Jequitinhonha e Mucuri, MGT 367, Km 583, CEP 39100-000, Diamantina (MG), Brasil. souzacmp@yahoo.com

5 Engenheiro Florestal, MSc., Gerente Florestal da Sada-Bio Energia, Av. Januário Ribeiro dos Santos, 455, CEP 39665-000, Carbonita (MG), Brasil. crodosilva@yahoo.com.br

Recebido para publicação em 19/07/2011 e aceito em 21/03/2017

Ci. Fl., v. 28, n. 2, abr. - jun., 2018 
$\mathrm{T} 4=125 \%$ ET0 - three times a day, T5 $=150 \%$ ET0 - three times a day, T6 $=100 \%$ ET0 - often single-T7 and the company operating Blade $-10.66 \mathrm{~mm}$ day-1, eight fertirrigation times a day for five minutes with a flow rate of $0.81 \mathrm{~h}-1$ ). They were assessed at ages $10,20,30,40$ and 50 days, the variables dry mass of minicuttings, root and total. The water irrigation level $2.19 \mathrm{~mm} /$ day-1 (T2) without foliar reduction showed the shortest the rooting time. The treatment without foliar reduction provided the minimizing of rooting time for all irrigation level managements (blades).

Keywords: vegetative propagation; dry mass; Class A tank.

\section{INTRODUÇÃO}

Uma das grandes preocupações relacionada à produção de mudas é em relação ao índice de enraizamento de miniestacas, refletindo na viabilidade econômica do viveiro.

A técnica de clonagem, a qual teve início em 1975 na República do Congo (DEWAULLE; LAPLACE; QUILLET, 1983), aliada às técnicas de miniestaquia e microestaquia, possibilitou ganhos econômicos e qualidade em função do maior índice de enraizamento, menor tempo para formação das mudas e maior uniformidade dos materiais.

Muitos fatores interferem no enraizamento das miniestacas: temperatura, umidade, composição química e física do substrato, adubação, luminosidade, a juvenilidade dos brotos, a posição do broto do qual as estacas são retiradas, diâmetro das estacas, a presença de gemas e/ou folhas, efeito do período de coleta das estacas, fotoperíodo e tratamento e/ou acondicionamento dos brotos e estacas antes da estaquia (HIGASHI; SILVEIRA; GONÇALVES, 2000). Todos estes fatores podem ser manejados no viveiro. No entanto, para cada material genético produzido há necessidade de adequar o manejo para obter o seu máximo de produtividade.

No viveiro, a primeira fase após o estaqueamento é o enraizamento das miniestacas, que dura em média 30 dias (15 dias na casa de vegetação e 15 dias na casa de sombra). Em geral, as adubações de cobertura por meio de fertirrigações iniciam-se na casa de sombra quando a plântula direciona a maior parte de seu metabolismo para a expansão da área foliar e para a formação de raízes. Após, as mudas seguem para a fase de aclimatação, em que a demanda de nutrientes é maior em função do rápido crescimento. Depois de 70 a 80 dias, as mudas já são destinadas para o plantio em campo (ALFENAS et al., 2004).

$\mathrm{O}$ tempo de permanência na casa de vegetação pode variar de acordo com cada material genético. $\mathrm{O}$ conhecimento desse tempo reflete diretamente na redução de gastos excessivos com a irrigação, dos riscos eminentes de doenças e a otimização do viveiro.

Deste modo o objetivo deste trabalho foi determinar o período ótimo de enraizamento das miniestacas de clone híbrido de Eucalyptus urophylla S.T. Blake e Eucalyptus grandis W. Hill ex Maiden na casa de vegetação e de sombra provenientes de minicepas submetidas a diferentes lâminas de irrigação aplicadas em minijardim e com e sem redução foliar da miniestaca.

\section{MATERIAL E MÉTODO}

O trabalho foi conduzido no viveiro da Empresa Sada Bio-Energia e Agricultura Ltda., em Sete

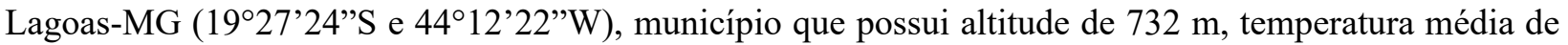
$21^{\circ} \mathrm{C}$ e precipitação total anual média de $1.340 \mathrm{~mm}$.

Adotou-se o delineamento em blocos casualizados, composto por seis lâminas de irrigação (T1, T2, T3, T4, T5 e T6) com quatro blocos e um tratamento adicional (T7). Os tratamentos T1 a T6 foram instalados em bacias plásticas circulares com área de $0,27 \mathrm{~m}^{2}$ preenchidas com areia e brita (Figura 1/Tabela 1). O preenchimento das bacias, o material genético e o espaçamento adotado simulam a condição operacional dos canaletões que compõem o minijardim clonal da empresa. Em cada bacia foram transplantadas 11 minicepas de 730 dias de idade de um clone híbrido de Eucalyptus urophylla S.T. Blake e Eucalyptus grandis W. Hill ex Maiden espaçadas $10 \times 10 \mathrm{~cm}$ entre si. Estas minicepas foram retiradas do canaletão operacional. O tratamento adicional (T7) foi estabelecido em quatro áreas de $0,27 \mathrm{~m}^{2}$ demarcadas no canaletão operacional da empresa em área limítrofe à área de instalação das bacias com minicepas do mesmo material genético e idade. Antes de aplicar os tratamentos T1 a T6, as minicepas transplantadas ficaram por 7 dias nas bacias 
para aclimatação.
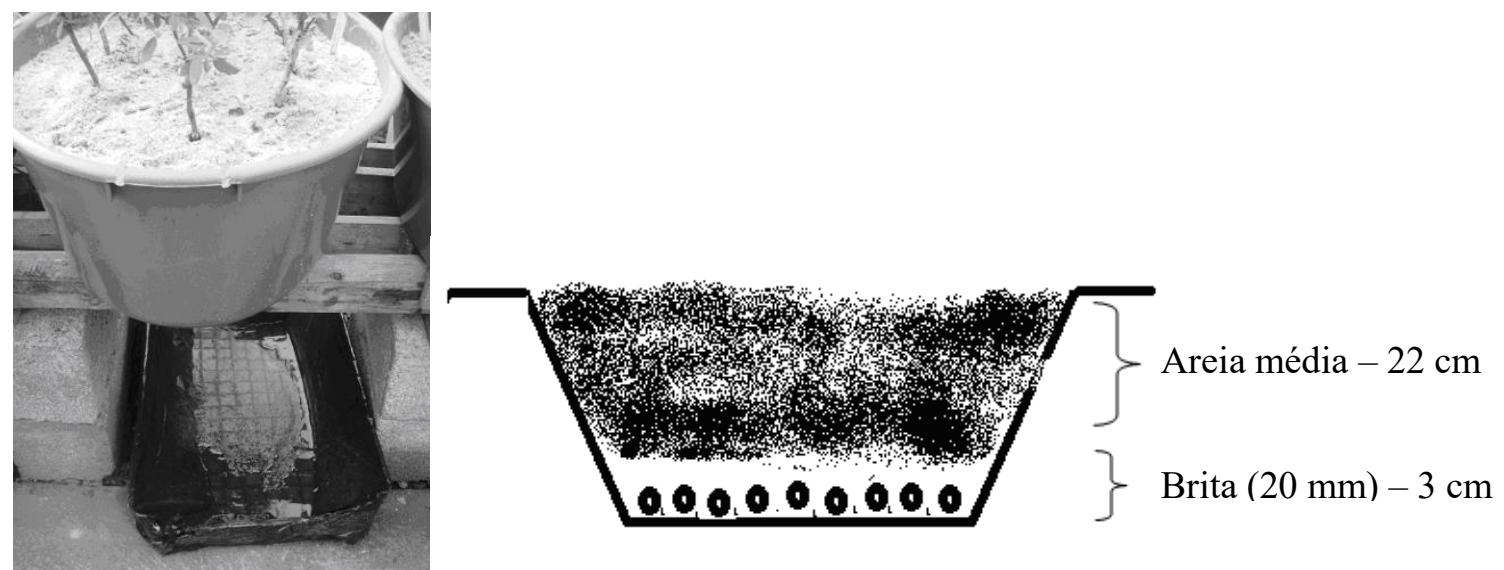

FIGURA 1: À esquerda, foto da unidade experimental e à direita desenho esquemático do corte transversal da unidade experimental.

FIGURE 1: Left photo of the experimental unit and, on the right, the cross-sectional schematic drawing of the experimental unit.

TABELA 1: Análise granulométrica da areia utilizada no minijardim clonal para a produção de minicepas.

TABLE 1: Particle size analysis of the sand used in clonal minigarden for producing ministumps.

\begin{tabular}{ccc}
\hline Areia $^{1}$ & Silte $^{1}$ & Argila $^{1}$ \\
\hline & --- ---- dag kg $^{-1}$-------- \\
\hline 95 & 2 & 3 \\
\hline
\end{tabular}

Em que: ${ }^{1}$ Método da pipeta

As lâminas de irrigação foram estabelecidas em função da leitura diária da evaporação (ET0) de um tanque Classe A instalado dentro da área do minijardim clonal. Os tratamentos foram definidos conforme consta na Tabela 2.

TABELA 2: Lâminas médias, calculadas através da evaporação do tanque Classe A (ET0), encontradas durante o período do experimento e aplicadas nos diferentes tratamentos.

TABLE 2: Medium depth, calculated using Class A tank, encountered during the experiment and applied in different treatments.

\begin{tabular}{cccc}
\hline Tratamentos & Lâminas (\% da ET0) & Lâmina $\left(\mathrm{mm} \mathrm{dia}^{-1}\right)$ & Frequência dia $^{-1}$ \\
\hline T1 & 50 & 1,46 & 1 \\
T2 & 75 & 2,19 & 2 \\
T3 & 100 & 2,92 & 2 \\
T4 & 125 & 3,65 & 3 \\
T5 & 150 & 4,38 & 3 \\
T6 & 100 & 2,92 & 1 \\
T7 & adicional & 10,66 & \\
\hline
\end{tabular}

Em que: $\mathrm{T} 7$ = adicional (operacional da empresa - lâmina 10,66 $\mathrm{mm} \mathrm{dia}^{-1}$, dividida em oito fertirrigações).

A frequência de irrigação para cada tratamento foi estabelecida de forma a não ultrapassar a capacidade de campo da areia.

A leitura no tanque Classe $\mathrm{A}$ foi realizada diariamente às $9 \mathrm{~h}$, sendo utilizado o método de reposição de volume. Para o cálculo da irrigação utilizou-se: ETc = Kc.ET0, onde, Etc $(\mathrm{mm})$ : evapotranspiração da 
espécie, Kc: coeficiente da cultura (adotado Kc = 1) e ET0 (mm): evaporação do tanque Classe A.

Para a fertirrigação, definiu-se a aplicação da lâmina de $1 \mathrm{~mm}$ para todos os tratamentos, exceto para tratamento adicional. Como em alguns tratamentos a irrigação era inferior a $1 \mathrm{~mm}$, padronizou-se a lâmina correspondente ao T1 (50\% do volume correspondente à leitura do tanque Classe A) para ser feita a fertirrigação em todos os tratamentos e a diferença era realizada por meio da adubação foliar. A solução utilizada foi retirada dos tanques de mistura que enviam esta para o minijardim e aplicada através da bomba costal.

A fertirrigação era composta por 15,89 g de $\mathrm{N}$ (nitrato de cálcio, MAP, sulfato de amônio), 3,62 g de $\mathrm{Ca}$ (nitrato de cálcio, cloreto de cálcio), 5,04 g de $\mathrm{Mg}$ (sulfato de magnésio), 21,46 g de $\mathrm{K}_{2} \mathrm{O}$ (cloreto de potássio), 17,39 g de $\mathrm{Cl}$ (cloreto de cálcio e de potássio), 13,8 g de $\mathrm{P}_{2} \mathrm{O}_{5}$ (MAP), 9,85 g de $\mathrm{S}$ (sulfato de amônio, sulfato de magnésio, sulfato de manganês, sulfato de cobre), $0,13 \mathrm{~g}$ de Fe (ferro quelatizado), 57,8 $\mathrm{g}$ de $\mathrm{B}$ (ácido bórico), 0,09 $\mathrm{g}$ de $\mathrm{Mn}$ (sulfato de manganês), 0,004 g de $\mathrm{Cu}$ (sulfato de cobre), 0,009 $\mathrm{g}$ de $\mathrm{Zn}$ (sulfato de zinco) e 0,002 g de Mo (molibdato de sódio) por litro.

As reduções foliares foram realizadas por corte transversal nas folhas em $50 \%$ das miniestacas apicais coletadas com 6-8 cm de altura, contendo um par de folhas completamente formado. Foram estaqueadas em tubetes cônicos de $50 \mathrm{~cm}^{3}$, a 1-2 $\mathrm{cm}$ de profundidade, sem tratamento de fito-hormônio de enraizamento. O substrato de enraizamento utilizado foi uma mistura de composto de vermiculita expandida, fibra da casca de coco e casca de arroz carbonizada (50:20:30), com adição de solução nutritiva composta por 0,58 g de $\mathrm{Ca}$ (cloreto de cálcio), 1,74 g de $\mathrm{K}_{2} \mathrm{O}$ (cloreto de potássio), 0,0175 g de $\mathrm{P}_{2} \mathrm{O}_{5}$ (MAP), 0,18 g de $\mathrm{Mg}$ (sulfato de magnésio), 0,0026 $\mathrm{g}$ de $\mathrm{Cu}$ (sulfato de cobre), 0,0036 g de $\mathrm{Zn}$ (sulfato de zinco), 1,395 g de $\mathrm{Cl}$ (cloreto de potássio), 1,71 g de $\mathrm{N}$ (MAP), 0,27 g de $\mathrm{S}$ (sulfato de magnésio, sulfato de cobre e sulfato de zinco) por litro.

Em seguida foram encaminhadas para a casa de vegetação, na qual receberam nova aleatorização. $\mathrm{O}$ experimento foi instalado em delineamento em blocos casualizados no arranjo fatorial, composto por seis lâminas de irrigação e o tratamento adicional (T1, T2, T3, T4, T5, T6 e T7), quatro blocos, com e sem redução foliar da miniestaca.

Em casa de vegetação, as mudas foram mantidas por 25 dias, com a irrigação realizada diariamente por meio de nebulização intermitente no período das $07 \mathrm{~h} 20$ às $17 \mathrm{~h}$, irrigando-se por 10 segundos a cada intervalo de 5 minutos. A temperatura variou entre 21,6 a $34,9^{\circ} \mathrm{C}$ e a umidade relativa em torno de $68,8 \%$. Não houve aplicação de fertilizantes foliares.

Após o período na casa de vegetação, as mudas foram transferidas para a casa de sombra por igual intervalo, para estabilização do processo rizogênico. Esta é coberta com sombrite que reduz a incidência solar em 50\%, e as laterais são cobertas com plástico para reduzir a incidência de vento. A irrigação foi feita por microaspersores durante 10 segundos em um intervalo de 10 minutos, no período das $08 \mathrm{~h} 30$ às $17 \mathrm{~h} 30$. Aplicou-se a solução de fertirrigação na primeira irrigação do dia, sendo a solução nutritiva composta de: $0,19 \mathrm{~g}$ de $\mathrm{N}$ (nitrato de cálcio, sulfato de amônio, ureia), 0,07 $\mathrm{g}$ de $\mathrm{Ca}$ (nitrato de cálcio), 0,25 $\mathrm{g}_{\text {de }} \mathrm{K}_{2} \mathrm{O}$ (cloreto de potássio), 0,25 g de $\mathrm{P}_{2} \mathrm{O}_{5}$ (MAP), 70,42 $\mathrm{g}$ de $\mathrm{S}$ (sulfato de amônio, sulfato de magnésio, sulfato de manganês, sulfato de zinco e sulfato de cobre), $0,02 \mathrm{~g}$ de $\mathrm{Mg}$ (nitrato de cálcio, sulfato de magnésio), $0,20 \mathrm{~g}$ de $\mathrm{Cl}$ (cloreto de potássio), 57,96 g de $\mathrm{B}$ (ácido bórico), 110,81 g de Mn (sulfato de manganês), 5,11 $\mathrm{g}$ de $\mathrm{Zn}$ (sulfato de zinco), 4,85 g de Cu (sulfato de cobre), 2,08 $\mathrm{g}$ de Mo (molibdato de sódio) por litro.

Avaliou-se o enraizamento aos 10, 20,30,40 e 50 dias após o estaqueamento. Para isto foi sorteada uma muda de cada tratamento. Quantificou-se a massa seca da parte aérea (MSPA), das raízes (MSR) e total (MST). Para se proceder às avaliações, o sistema radicular foi separado da parte aérea e, após remover os resíduos de substrato, procedeu-se à secagem em estufa com ventilação forçada a $70^{\circ} \mathrm{C}$, durante 72 horas. Em seguida, determinou-se a biomassa seca de cada parte da muda em balança de precisão.

Os dados foram submetidos à análise de variância. As médias das lâminas de irrigação e redução foliar foram comparadas pelo teste de Tukey a 5\% e as épocas de avaliação pela análise de regressão.

\section{RESULTADOS E DISCUSSÃO}

Existe correlação entre a matéria seca da parte aérea (MSPA) em função das épocas avaliadas e as lâminas de irrigação, sendo que para a maioria dos ajustes, a equação foi linear (Figura 2). 
Entre as idades de 10 a 20 dias os valores da MSPA ficaram próximos. A partir dos 20 dias, a produção de MSPA começou a diferenciar, sendo que, ao final dos 50 dias, a maior produção de MSPA foi referente à lâmina de 10,66 mm dia-1 (T7). As lâminas 2,19 mm dia ${ }^{-1}$ (T2), 2,92 $\mathrm{mm} \mathrm{dia}^{-1}$ (T3) e 4,38 mm $\operatorname{dia}^{-1}$ (T5) obtiveram sua máxima produção em MSPA entre as idades de 20 a 35 dias (Figura 2).

Apesar da lâmina T3 ser igual a T6 $\left(2,92 \mathrm{~mm} \mathrm{dia}^{-1}\right)$, diferindo apenas na frequência das irrigações, a produção de MSPA foi maior para T6 (Figura 2). A mesma tendência foi seguida pela MSR (Figura 3). As frequências das lâminas de irrigação podem ter influenciado na produção de massa seca, bem como no enraizamento. Se a umidade do solo/substrato for constantemente mantida na capacidade de campo, o desenvolvimento do sistema radicular será mínimo, porque a raiz não precisará crescer para conseguir água, sendo que regas abundantes, porém, espaçadas, permitem que o solo/substrato seque até o ponto de murchamento, favorecendo o crescimento do sistema radicular e consequentemente, a absorção de nutrientes (STURION; ANTUNES, 2000).

Da mesma forma que ocorreu para T3 e T6, para as lâminas de 2,19 $\mathrm{mm} \mathrm{dia}^{-1}$ (T2) e 4,38 mm dia ${ }^{-1}$ (T5), o acúmulo de MSPA acompanha o acúmulo de MSR (Figuras 2 e 3). Este fato explica o comportamento quadrático da produção de MSPA, com o aumento da MSR favorecendo a absorção de água e nutrientes, e, consequentemente, uma maior produção de MSPA.

Em relação à redução foliar, para todas as lâminas de irrigação o tratamento sem redução apresentou uma maior produção de MSPA do que os com redução foliar (Figura 2). Além disso, para o tratamento sem redução foliar, a lâmina de $10,66 \mathrm{~mm} \mathrm{dia}^{-1}$ (T7) apresentou uma maior média de MSPA, porém, quando se observa o tratamento com redução foliar, essa diferença é inexistente (Figura 2). Os resultados observados por Santana et al. (2009) corroboram o do presente estudo, ou seja, maior MSPA foi observada nos tratamentos nos quais não ocorreu redução foliar. Esses autores atribuíram a maior produção à redução do estresse promovido pela redução foliar e pela folha completa possuir maior reserva de nutrientes e carboidratos em relação à folha que sofreu o procedimento.
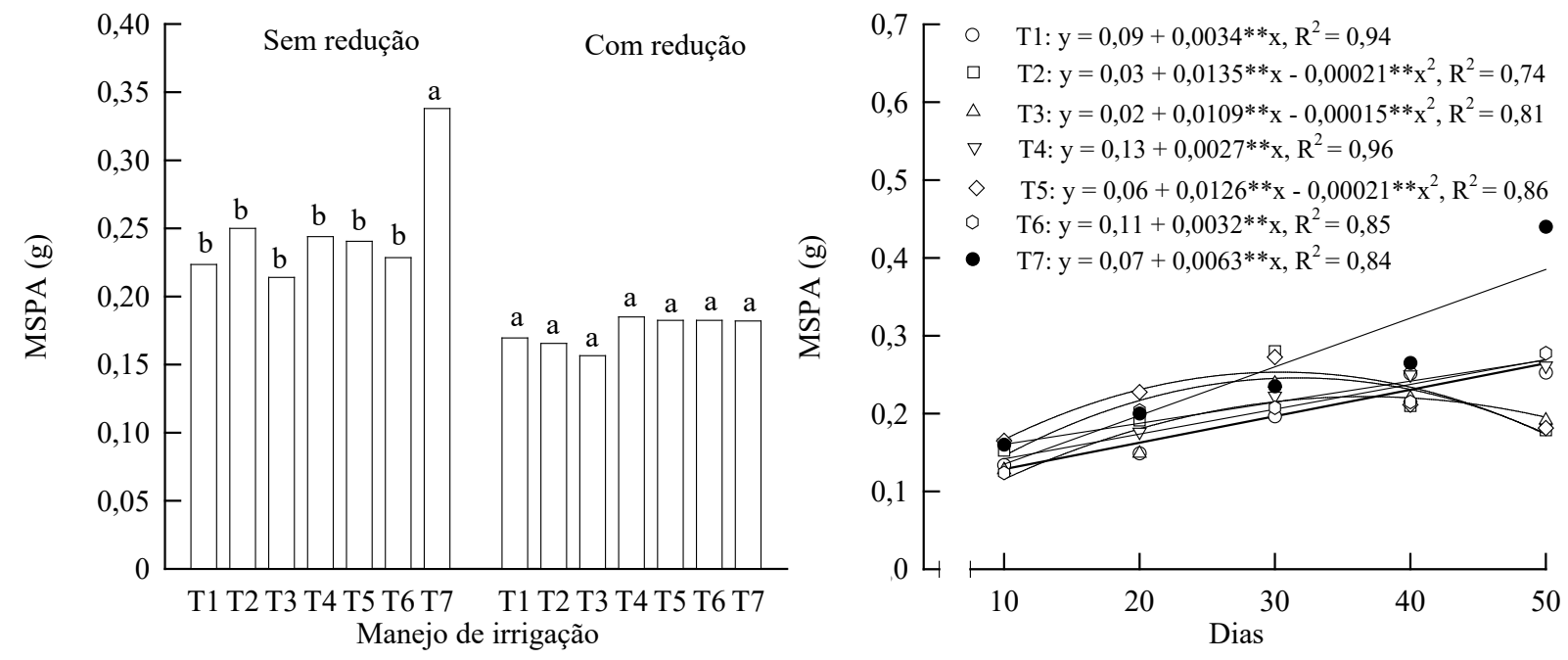

FIGURA 2: Produção de massa seca da parte aérea (MSPA) de mudas de eucalipto em função do manejo de irrigação (T1, T2, T3, T4, T5, T6 e T7) no minijardim clonal avaliadas em cinco épocas (10, 20, 30, 40 e 50 dias), com e sem redução foliar. (** Significativo a 1\% pelo teste $t$ ).

FIGURE 2: Dry mass of shoot (MSPA) of eucalyptus as a function of irrigation management (T1, T2, T3, T4, T5, T6 and T7) in the minihedge clonal evaluated in five seasons (10, 20, 30, 40 and 50 days), reduction with and without foliar. (**Significant at $1 \%$ by test $t$ ). 

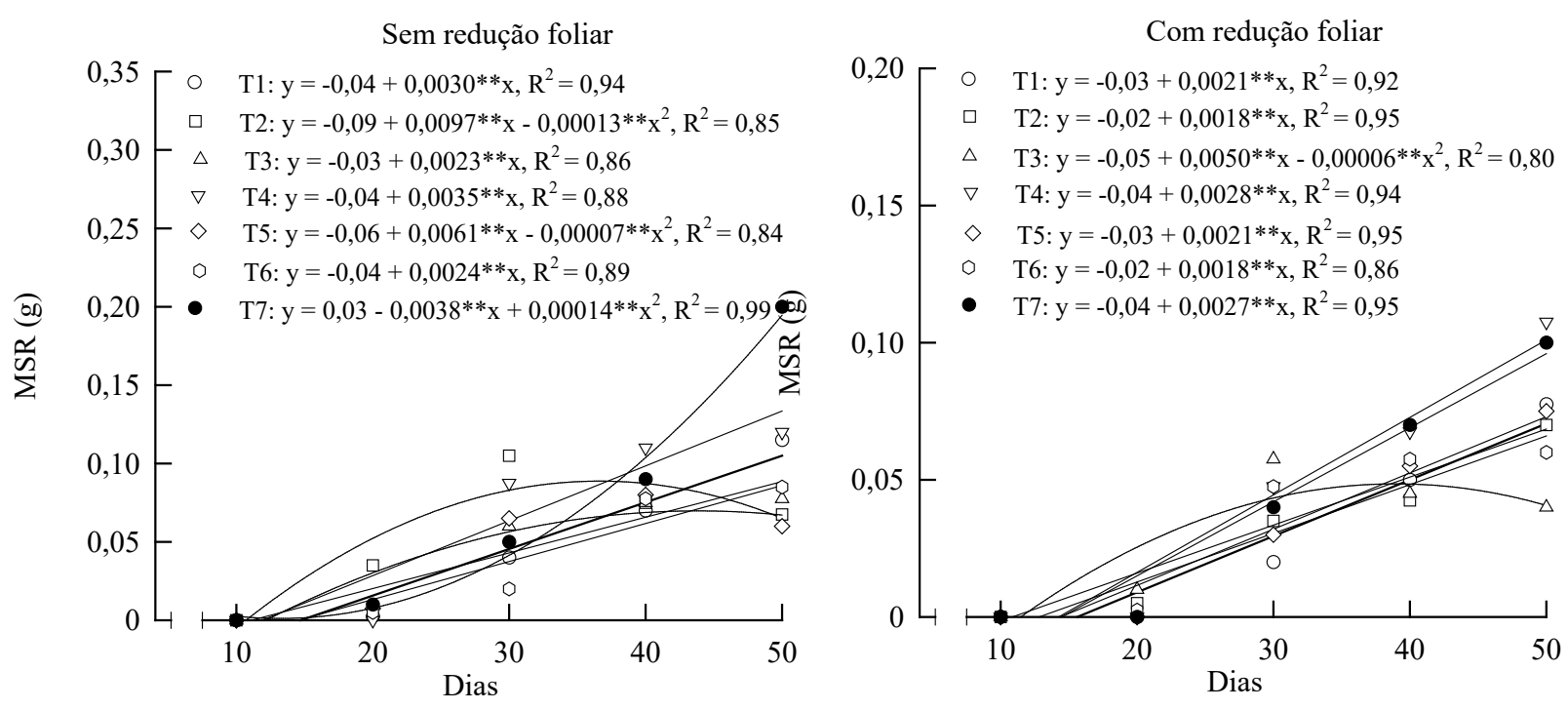

FIGURA 3: Produção de massa seca de raízes (MSR) de mudas de eucalipto em função do manejo de irrigação (T1, T2, T3, T4, T5, T6 e T7) no minijardim clonal avaliadas em cinco épocas (10, 20, 30, 40 e 50 dias), com e sem redução foliar. $(* *$ Significativo a $1 \%$ pelo teste de $t$ ).

FIGURE 3: Dry mass of root (MSR) of eucalyptus as a function of irrigation management (T1, T2, T3, T4, T5, T6 and T7) in the minihedge clonal evaluated in five seasons (10, 20, 30, 40 and 50 days), reduction with and without foliar (**Significant at $1 \%$ by test $\mathrm{t})$.

Para todas as irrigações, o tratamento sem redução foliar foi superior ao tratamento com redução foliar para produção de MSR (Figura 3). Segundo Cunha (2006), a presença de folhas nas estacas estimula o enraizamento, por permitir que ocorra a fotossíntese, sendo seus produtos (particularmente carboidratos e auxinas) fundamentais para a iniciação radicular. Nas folhas que não sofreram redução, pode-se encontrar um maior acúmulo de carboidratos e auxinas, favorecendo a produção da MSR. Desta forma, ganhos podem ser evidenciados com a não redução foliar, por exemplo, a redução do tempo de confecção das miniestacas. A recomendação de não realizar a redução foliar na miniestaca de eucalipto permite um desenvolvimento semelhante a com redução foliar, não causando estresse, reduzindo o risco de ocorrerem doenças foliares causadas por contaminação por fungos (SANTANA et al., 2010).

No período entre 10 a 30 dias, para o tratamento sem redução foliar, a lâmina de $2,19 \mathrm{~mm} \mathrm{dia}^{-1}$ (T2) foi superior às demais, enquanto para o tratamento com redução foliar a lâmina de 2,92 $\mathrm{mm} \mathrm{dia}^{-1}$ (T3) obteve a maior média em relação a MSR (Figura 3). A partir dos 30 dias, para as duas irrigações (T2 e T3) houve uma estabilização, sendo a maior produção de MSR obtida pela lâmina de 10,66 mm dia-1 ${ }^{-1}$ T) (Figura 3).

Para todas as lâminas de irrigação do minijardim clonal, as miniestacas sem redução foliar apresentaram maior produção de MST em comparação ao tratamento com redução foliar (Figura 4). Aos 10 dias de idade, não há diferença significativa entre as irrigações para a MST, com e sem redução foliar. A partir dos 20 dias, as lâminas de 2,19 $\mathrm{mm} \mathrm{dia}^{-1}$ (T2) e 2,92 $\mathrm{mm} \mathrm{dia}^{-1}$ (T6) apresentaram as maiores médias, para os tratamentos sem e com redução foliar da miniestaca, respectivamente. Essa situação se manteve até os 30 dias. A partir daí, a lâmina de 10,66 mm dia-1 (T7) apresentou a maior média de MST até o final do experimento (Figura 4). Este fato pode ser relacionado a uma possível estabilização da produção em massa seca total, das demais irrigações, já que geralmente, por cerca de 5-10 dias, as mudas são aclimatadas à sombra para estabilização do processo rizogênico (ALFENAS et al., 2004). Além disso, estudos sobre eficiência do uso da água mostram que a produção de matéria seca total é linearmente proporcional à quantidade de água utilizada (SILVA, 2003).

Como as mudas permaneceram 25 dias na casa de vegetação e mais 25 na casa de sombra, pode-se concluir que a rizogênese do manejo do tratamento T7 $\left(10,66 \mathrm{~mm} \mathrm{dia}^{-1}\right)$, assim como para os demais que tiveram produção da MSR linear (Figura 3), foi completada na fase da casa de sombra. Segundo Alfenas et 
al. (2004), para alguns materiais de rizogênese mais lenta e em determinadas estações de ano, o enraizamento completa-se na casa de sombra.

Geralmente a fase de enraizamento dura em média 25 a 35 dias (ALFENAS et. al., 2004), podendo ser reduzida para 20 a 30 dias, sendo de 10-15 dias na casa de vegetação e de 5-7 dias na casa de sombra (FERREIRA et al., 2004). O enraizamento de estacas pode ser influenciado por injúrias, pelo balanço hormonal, pela constituição genética da matriz, pela presença de inibidores e pelas condições nutricionais e hídricas da planta doadora de propágulos (ALFENAS et al., 2004).
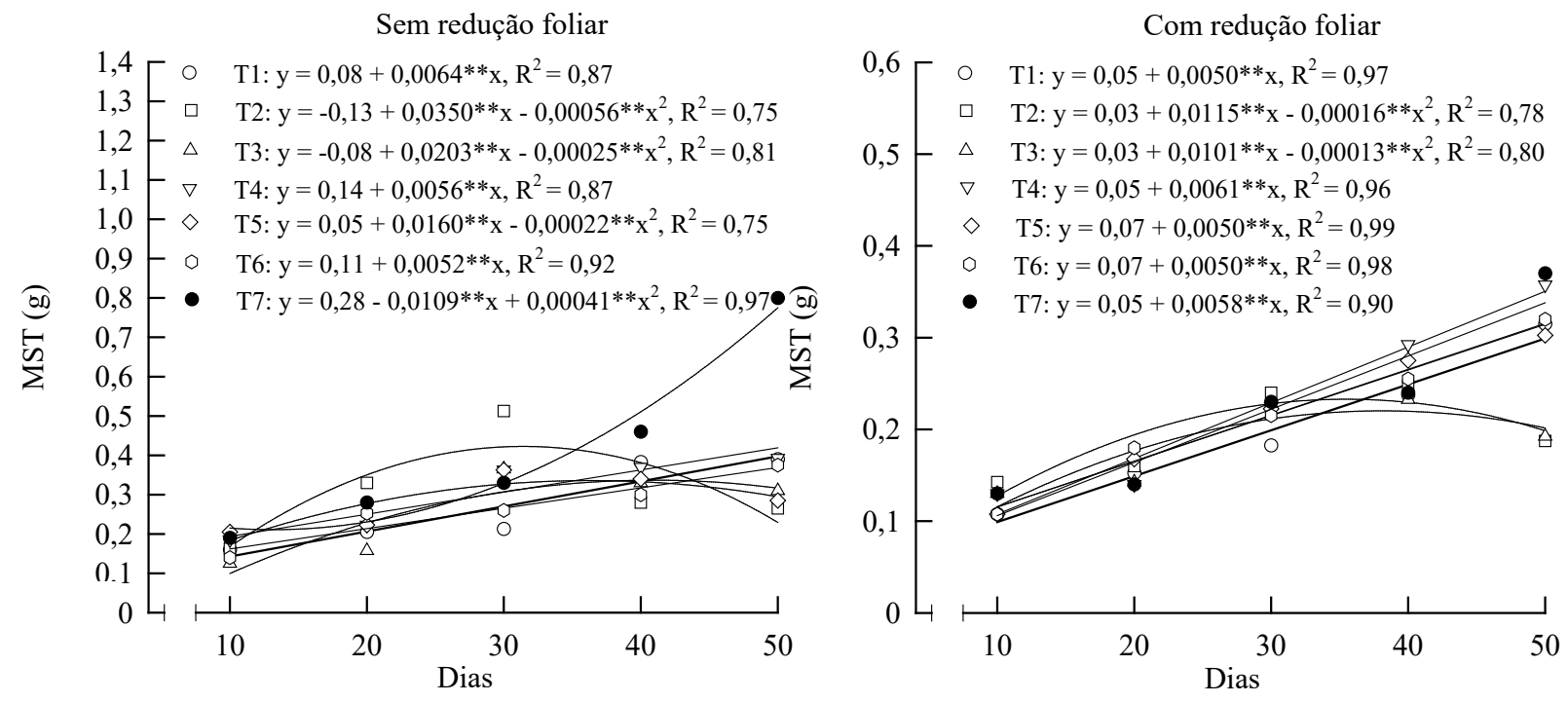

FIGURA 4: Produção de massa seca total (MST) de mudas de eucalipto em função do manejo de irrigação (T1, T2, T3, T4, T5, T6 e T7) no minijardim clonal avaliadas em cinco épocas, com e sem redução foliar. (** Significativo a $1 \%$ pelo teste de $\mathrm{t}$ ).

FIGURE 4: Production of total dry mass (MST) of eucalyptus as a function of irrigation management (T1, T2, T3, $\mathrm{T} 4, \mathrm{~T} 5, \mathrm{~T} 6$ and T7) in the minihedge clonal evaluated in five seasons, reduction with and without foliar (** Significant at $1 \%$ by test $\mathrm{t}$ ).

Vários autores determinaram a MSPA e a MSR para mudas de eucalipto em diferentes idades (Tabela 3). Todas as lâminas de irrigação sem redução foliar tiveram valores superiores aos que foram encontrados por Titon, Xavier e Otoni $(2002 ; 2006)$ e Mafia et al. $(2005 ; 2007)$. Para os tratamentos com redução foliar, somente a lâmina de $2,92 \mathrm{~mm} \mathrm{dia}^{-1}$ (T6) alcançou valores esperados aos 21 dias, sendo que a partir desta idade todas as lâminas de irrigação alcançaram os valores observados pelos autores (Tabela 3).

No período entre 10 a 30 dias, para o tratamento sem redução foliar, a lâmina de $2,19 \mathrm{~mm} \mathrm{dia}^{-1}$ (T2) foi superior aos demais, enquanto para o tratamento com redução foliar a lâmina de 2,92 mm dia-1 (T3) possuiu a maior média (Figura 3). Para as demais lâminas, esse valor foi alcançado aos 40 dias (Figura 3). Os tratamentos com redução foliar, somente aos 50 dias alcançaram valores superiores ao limite proposto, exceto para as lâminas de $2,19 \mathrm{~mm} \mathrm{dia}^{-1}$ (T2) e de $2,92 \mathrm{~mm} \mathrm{dia}^{-1}$ (T3 e T6 - frequência única) (Figura 3).

Em relação à produção de MSPA, aos 20 dias as lâminas de 2,19 $\mathrm{mm} \mathrm{dia}^{-1}$ (T2) e de 2,92 $\mathrm{mm}$ dia${ }^{1}$ (T6) sem redução foliar alcançaram valores referentes aos 50 dias encontrados por Wendling e Xavier (2005). Os demais tratamentos alcançaram esses valores descritos pelos autores aos 30 dias, exceto para as lâminas 1,46 mm dia-1 (T1) e 10,66 mm dia-1 (T7), que alcançaram aos 40 dias (Figura 2). Para os tratamentos com redução, somente aos 50 dias foram alcançados valores na faixa proposta, exceto para as lâminas 2,19 mm dia-1 (T2), 2,92 mm dia-1 (T3) e 4,38 $\mathrm{mm} \mathrm{dia}^{-1}$ (T5), que não alcançaram esses valores (Figura 2). 
TABELA 3: Produção de matéria seca da parte aérea (MSPA) e radicular (MSR) de mudas de eucalipto observada pelos autores, de acordo com a idade.

TABLE 3: Production of shoot dry matter (MSPA) and roots (MSR) of eucalyptus observed by the authors, according to age.

\begin{tabular}{cccl}
\hline Dias & MSPA $\left(\mathrm{g} \mathrm{planta}^{-1}\right)$ & MSR $\left(\mathrm{g} \mathrm{planta} \mathrm{a}^{-1}\right)$ & \multicolumn{1}{c}{ Autor } \\
\hline 21 & - & $0,0012-0,0023$ & Titon et al. (2006) \\
25 & - & $0,0220-0,0360$ & Mafia et al. (2007) \\
28 & - & $0,0180-0,0320$ & Titon et al. (2002) \\
30 & - & $0,0150-0,0300$ & Mafia et al. (2005a) \\
40 & $0,1800-0,2000$ & $0,0100-0,0120$ & Mafia et al. (2005b) \\
42 & $0,1000-0,1500$ & $0,0400-0,0600$ & Gruber (2006) \\
50 & - & $0,0390-0,0700$ & Wendling e Xavier (2005) \\
50 & $0,2400-0,4500$ & - & Wendling e Xavier (2003) \\
\hline
\end{tabular}

Portanto, quando se avaliam os dados em conjunto, a lâmina 2,19 $\mathrm{mm} \mathrm{dia}^{-1}$ (T2) sem redução foliar da miniestaca apresentou o menor tempo de enraizamento, alcançando no período de 20 a 30 dias valores ótimos de massa seca antes do tempo proposto pela literatura. Ferreira et al. (2004) determinaram o tempo ótimo de enraizamento de 15 a 30 dias para dois clones de eucalipto, corroborando os resultados encontrados neste trabalho.

Entre os principais fatores que afetam a propagação vegetativa pelo enraizamento de estacas estão aqueles relacionados com o genótipo, com as condições fisiológicas da planta fornecedora das estacas, com o tipo de estaca, com a nutrição mineral (vigor vegetativo da planta-matriz e estado nutricional do material coletado), com o tratamento das estacas (armazenamento, aplicação de reguladores de crescimento, antioxidantes e cofatores) e com a manipulação das condições ambientais, quanto à luminosidade, umidade, temperatura e substrato (GREENWOOD; HUTCHISON, 1993; HARTMANN; KESTER, 2002; TAIZ; ZEIGER, 2004).

Além disso, outro fator importante no enraizamento das miniestacas é a presença de folhas. A contribuição das folhas decorre da produção de carboidratos necessários para promover o enraizamento (COOPER, 1990). As folhas e gemas são também produtoras de auxinas, substâncias estas que tem grande influência na formação de raízes em estacas (KRAMER et al., 1972; HARTMANN; KESTER, 2002).

A não redução foliar das miniestacas demonstrou-se viável, já que não foi constatada a ocorrência de doenças fitopatogênicas durante a fase experimental e houve redução no tempo de enraizamento das estacas. É necessário considerar como critério o risco crescente de doenças na casa de vegetação e de sombra com o decorrer do tempo, em virtude das condições predominantes de temperatura e umidade elevadas, o que favorece o desenvolvimento de microrganismos (FERREIRA et al., 2004).

A lâmina de irrigação T2 é apenas aproximadamente $21 \%$ da lâmina do tratamento adicional, que é o operacionalizado na empresa, aplicada em uma mesma área, indicando que há um consumo de água em excesso e sem necessidade na irrigação das minicepas no minijardim clonal. Segundo Sturion e Antunes (2000), as regas no viveiro devem ser abundantes e espaçadas para permitir que o substrato seque nos intervalos, até próximo do ponto de murchamento. Nessas condições, as mudas apresentarão sistema radicular bem desenvolvido e consequentemente maior probabilidade de sobrevivência em campo.

Uma das grandes preocupações nos viveiros clonais e que afeta diretamente a produtividade e enraizamento das miniestacas é a disponibilidade de água. Freitag (2007) observou que, nos viveiros em Santa Maria-RS, para a produção de 100.000 mudas ano $^{-1}$, são necessários, aproximadamente, 10.000 litros de água. Na região de Martinho Campos-MG, para a produção de 12 milhões de mudas ao ano, o consumo de água é elevado, chegando a $592 \mathrm{~m}^{3} \mathrm{dia}^{-1}$ nos minijardins clonais, sendo que em uma etapa do processo, o volume drenado (excesso) por canaletão chega a $40 \%$ do total aplicado (RODRIGUES, 2007). Entretanto, consumos de água bem superiores ao anteriormente citado são observados em vários viveiros florestais que não adotam um processo técnico para estabelecimento da irrigação, ou seja, deixando-a sob responsabilidade do critério empírico do viveirista. Essa perda em água promove lixiviação dos nutrientes e não absorção adequada desses pelas minicepas, reduzindo a qualidade, produtividade e enraizamento das miniestacas, e refletindo em perda financeira para o viveiro. 
Vários autores definiram uma lâmina adequada para a produção de espécies florestais, levando em consideração material genético, substrato, temperatura, umidade relativa do ar e sistema do minijardim. Higashi e Silveira (2004) recomendaram para o minijardim clonal de eucalipto via gotejamento a lâmina de 5 a $8 \mathrm{~mm} \mathrm{dia}^{-1}$. Galbiatti et al. (2007) verificaram que lâminas entre 50 e $75 \%$ da ET0 para a produção de eucalipto podem ser utilizadas em minijardim com substrato de resíduos sólidos orgânicos urbanos. Com os resultados obtidos nesse estudo, uma lâmina menor do que as encontradas na literatura citada ( $21 \%$ da ET0) foi viável na produção de mudas, resultando na redução do consumo de água, energia e adubo, mantendo a qualidade da muda.

\section{CONCLUSÕES}

O menor período de enraizamento foi de 20 a 30 dias referente à lâmina aplicada no minijardim clonal de 2,19 $\mathrm{mm} \mathrm{dia}^{-1}$, sem redução foliar da miniestaca.

$\mathrm{O}$ tratamento sem redução da área foliar proporcionou o menor tempo de enraizamento para todas as lâminas de irrigação, podendo ser adotado para a produção de mudas provenientes da miniestaquia.

\section{AGRADECIMENTOS}

À Universidade Federal dos Vales do Jequitinhonha e Mucuri (UFVJM), à Coordenação de Aperfeiçoamento de Pessoal de Nível Superior (CAPES) e à Empresa Sada Bio-Energia e Agricultura Ltda.

\section{REFERÊNCIAS}

ALFENAS, A. C. et al. Clonagem e doenças do eucalipto. Viçosa, MG: UFV, 2004. 442 p. COOPER, M. A. Maximizaçao do potencial de enraizamento de estacas de Eucalyptus dunnii Maiden. 1990. 90 f. Dissertação (Mestrado em Ciência Florestal) - Universidade Federal do Paraná, Curitiba, 1990. CUNHA, A. C. M. C. M. Relações do estado nutricional de minicepas e condições metereológicas com o número e o enraizamento de miniestacas de eucalipto. 2006. 99 f. Dissertação (Mestrado em Ciência Florestal) - Universidade Federal de Viçosa, Viçosa, MG, 2006.

DEWAULlE, J. C.; LAPLACE, Y.; QUILLET, G. Production massive de boutures d' Eucalyptus em République Populaire du Congo. Silvicultura, São Paulo, v. 8, n. 32, p. 779 -781, 1983.

FERREIRA, E. M. et al. Determinação do tempo ótimo do enraizamento de miniestacas de clones de Eucalyptus spp. Revista Árvore, Viçosa, MG, v. 28, n. 2, p. 183-187, 2004.

FREITAG, A. S. Frequências de irrigação para Eucalyptus grandis e Pinus elliottii em viveiro. 2007. 60 f. Dissertação (Mestrado em Engenharia Agrícola) - Universidade Federal de Santa Maria, Santa Maria, 2007.

GREENWOOD, M. S.; HUTCHISON, K. W. Maturation as a development process. In: AHUJA, M. R.; LIBBY, W. J. (Ed.). Clonal forestry: genetics and biotechnology. Budapest: Springer-Verlag, 1993. p. 14-33.

GALBIATTI, J. A. et al. Formação de mudas de eucalipto com utilização de lixo orgânico e níveis de irrigação calculados por dois métodos. Engenharia Agrícola, Jaboticabal, v. 27, n. 2, p. 445-455, maio/ ago. 2007.

GRUBER, Y. B. G. Otimização da lâmina de irrigação na produção de mudas clonais de eucalipto (Eucalyptus urophylla $x$ Eucalyptus grandis e Eucalyptus urophylla var. plathyphylla). 2006. $144 \mathrm{f}$. Dissertação (Mestrado em Agronomia) - Escola Superior Luiz de Queiroz, Piracicaba, 2006.

HARTMANN, H. T.; KESTER, H. D. Plant propagation: principles and practices. 7th ed. New Jersey: Prentice-Hall, 2002. 880 p.

HIGASHI, E. N.; SILVEIRA, R. L. A. Fertirrigação em viveiros de mudas de Eucalyptus e Pinus. In: BOARETTO, A. E. et al (Ed.). Fertirrigação: teoria e prática. Piracicaba: [s. n.], 2004. v. 1. p. 677-725.

HIGASHI, E. N.; SILVEIRA, R. L. V. A.; GONÇALVES, A. N. Monitoramento nutricional e fertilização em macro, mini e microjardim clonal de Eucalyptus. In: GONÇALVES, J. L. M.; BENEDETTI, V. (Ed.). Nutrição e fertilização florestal. Piracicaba: IPEF, 2000. p. 191-218. 
KRAMER, R. J.; KOSLOWSKI, T. T. Fisiologia das árvores. Lisboa: Fundação Kalouste Gouldbenkian, 1972. 745p.

MAFIA, R. G. et al. Crescimento de mudas e produtividade de minijardins clonais de eucalipto tratados com rizobactérias selecionadas. Revista Árvore, Viçosa, MG, v. 29, n. 6, p. 843-851, 2005. (a)

MAFIA, R. G. et al. Critério técnico para determinação da idade ótima de mudas de eucalipto para plantio. Revista Árvore, Viçosa, MG, v. 29, n. 6, p. 947-953, 2005. (b)

MAFIA, R. G. et al. Indução do enraizamento e crescimento do eucalipto por rizobactérias: efeito da adição de fonte alimentar e da composição do substrato de enraizamento. Revista Árvore, Viçosa, MG, v. 31, n. 4, p. 589-597, 2007.

RODRIGUES, S. B. S. Análise do uso da água em unidades de produção de mudas de eucaliptos. 2007. 93 f. Dissertação (Mestrado em Engenharia Agrícola) - Faculdade de Engenharia Agrícola, Universidade Federal de Viçosa, Viçosa, MG, 2007.

SANTANA, R. C. et al. Influence of leaf area reduction on clonal porduction of Eucalyptus seedlings. Cerne, Lavras, v. 16, n. 3, p. 251-257, 2010.

SANTANA, R. C. et al. Influência da redução foliar no crescimento e enraizamento de mudas clonais de eucalipto em escala operacional. In: CONGRESSO BRASILEIRO DE CIÊNCIA DO SOLO, 32., 2009, Fortaleza. Anais... Fortaleza: SBCS, 2009. 1 CD-ROOM.

SILVA, M. R. Efeitos do manejo hídrico e da aplicação de potássio na qualidade de mudas de Eucalyptus grandis W. (Hill ex. Maiden). 2003. 116 f. Tese (Doutorado em Agronomia) - Universidade Estadual de São Paulo, Campus Botucatu, São Paulo, 2003.

STURION, J. A.; ANTUNES, B. M. A. Produção de mudas de espécies florestais. In: GALVÃO, A. P. M. Reflorestamento de propriedades rurais para fins produtivos e ambientais. Colombo: EMBRAPA, 2000. p. 125-150.

TAIZ, L.; ZEIGER, E. Fisiologia Vegetal. 3. ed. Porto Alegre: Artemed, 2004. 719 p.

TITON, M.; XAVIER, A.; OTONI, W. C. Clonal propagation of Eucalyptus grandis using the mini-cutting and micro-cutting techniques. Scientia Forestalis, Piracicaba, n. 71, p. 109-117, 2006.

TITON, M.; XAVIER, A.; OTONI, W. C. Dinâmica do enraizamento de microestacas e miniestacas de clones de Eucalyptus grandis. Revista Árvore, Viçosa, MG, v. 26, n. 6, p. 665-673, 2002.

WENDLING, I.; XAVIER, A. Influência da miniestaquia seriada no vigor radicular de clones de Eucalyptus grandis. Revista Árvore, Viçosa, MG, v. 29, n. 5, p. 681-2005.

WENDLING, I.; XAVIER, A. Miniestaquia seriada no rejuvenescimento de clones Eucalyptus. Pesquisa Agropecuária Brasileira, Brasília, v. 38, n. 4, p. 475-480, 2003. 